\title{
Physical function in patients newly diagnosed with multiple myeloma; a Danish cohort study
}

Rikke Faebo Larsen ${ }^{1,2,3^{*}}$ D, Mary Jarden ${ }^{4,5}$, Lisbeth Rosenbek Minet ${ }^{2,6,7}$, Ulf Christian Frølund ${ }^{8}$, Sören Möller ${ }^{2,3}$ and Niels Abildgaard ${ }^{2,9,10}$

\begin{abstract}
Background: Multiple myeloma is a cancer in the bone marrow causing bone destruction. Patients experience various symptoms related to the disease and/or treatment, such as pain and fatigue, leading to poorer quality of life. The symptom burden might affect physical function and physical activity levels, posing a risk of physical deterioration. The aim was to investigate whether physical function in newly diagnosed patients with multiple myeloma differs from the reference values of the normal population and other cancer patients.

Methods: The study is a cross sectional descriptive analysis of a prospective cohort of 100 patients newly diagnosed with multiple myeloma. Four physical function tests were carried out; Six-Minute-Walk-Test, Sit-to-StandTest, grip strength and knee extension strength. Age and gender specific results of physical function from the multiple myeloma population were compared to normative data and to data from other cancer populations.

Results: Of the 100 patients included, 73\% had bone disease and 55\% received pain relieving medicine. Mean age was 67.7 years (SD 10.3). Patients with multiple myeloma had significantly poorer physical function compared to normative data, both regarding aerobic capacity and muscle strength, although not grip strength. No differences in physical function were found between patients with multiple myeloma and other cancer populations.

Conclusions: Physical function in newly diagnosed Danish patients with multiple myeloma is lower than in the normal population. Exercise intervention studies are warranted to explore the value of physical exercise on physical function.
\end{abstract}

Trial registration: ClinicalTrials.gov, ID NCT02439112, registered 8 May 2015.

Keywords: Multiple myeloma, Bone disease, Physical function, Reference values, Cross sectional

\section{Background}

Multiple myeloma (MM) is a plasma cell cancer in the bone marrow that primarily affects older adults. In Europe the incidence of MM is 5.72 per 100,000 , and the median age at diagnosis is 68 years $[1,2]$. A hallmark of MM is the associated bone disease, which includes bone destructions, vertebral collapses and other pathological bone fractures, and hypercalcemia. Bone involvement is

\footnotetext{
* Correspondence: rikke.faebo.larsen@rsyd.dk

'Department of Physiotherapy and Occupational Therapy, Zealand University Hospital, Roskilde, Denmark

${ }^{2}$ Department of Clinical Research, University of Southern Denmark, Odense, Denmark

Full list of author information is available at the end of the article
}

seen in about $79 \%$ of newly diagnosed patients with MM [3]. In addition, anemia is common, presenting in approximately $73 \%$ of patients with MM [3]. Patients newly diagnosed with MM report low quality of life and reduced physical function, and pain and fatigue are dominant symptoms [4-7]. Moreover, patients with MM experience a greater symptom burden and more severe symptoms than patients with other malignant haematological diseases, negatively affecting their quality of life, especially, role, physical, and social function [8]. At time of diagnosis, global quality of life is affected and all five functional scales (physical, role, social, emotional, and cognitive functioning) on EORTC are negatively affected.

(c) The Author(s). 2020 Open Access This article is distributed under the terms of the Creative Commons Attribution 4.0 International License (http://creativecommons.org/licenses/by/4.0/), which permits unrestricted use, distribution, and reproduction in any medium, provided you give appropriate credit to the original author(s) and the source, provide a link to the Creative Commons license, and indicate if changes were made. The Creative Commons Public Domain Dedication waiver (http://creativecommons.org/publicdomain/zero/1.0/) applies to the data made available in this article, unless otherwise stated. 
Pain and fatigue are the most prevalent and distressing symptoms $[9,10]$.

Physical fitness, including endurance, strength, flexibility, and balance, is associated with physical function, physical functional limitation and physical independence [11, 12]. Physical indicators, such as low level of physical activity, lower extremity function, and low grip strength can predict disabilities related to activities of daily living, e.g. walking, transferring, bathing or dressing [13]. Mobility limitations 30 days after discharge among older medical patients can be predicted by measurements of handgrip strength, gait speed, modified chair stand test and the Cumulated Ambulation Score, where chair stand test (Sit-to-Stand-Test) and gait speed are the strongest predictors [14]. Thus, both aerobic capacity and strength are important for physical function in daily life, not least in the older population, since physical fitness is associated with age $[11,12]$, and improved physical function may positively affect quality of life.

Though not being the only determining factor, physical function contributes significantly to the performance status of a patient, exemplified when the Eastern Cooperative Oncology Group (ECOG) performance status of a patient is assessed. In patients with MM, affected ECOG performance status, particularly performance status $3-4$, is a major predictor of an adverse prognosis $[15,16]$.

In spite of the bone destructive nature of MM and well described low patient-reported physical function levels, we have not been able to identify studies that report the objective physical function among newly diagnosed patients with MM. By testing physical function, patients at risk could be identified, and interventions to prevent physical deterioration or improve physical function could be initiated. Maintaining or improving physical function is fundamental for the patients to carry out usual activities and in maintaining their quality of life $[17,18]$. The effect of exercise in cancer patients is well documented [19], as well as in the elderly [20]. In patients with MM physical training has been shown to be safe and feasible [21, 22]. Furthermore, knowledge about whether and how patients with MM differ from other cancer populations would be helpful for clinical practice in the planning of exercise interventions.

We hypothesised, that patients with MM have poorer physical function than the normal population and patients with other cancer diagnoses. The aim of this study was to describe age and gender specific physical function among patients newly diagnosed with multiple myeloma and to compare physical function to the normal population and other cancer populations.

\section{Methods}

This is a cross sectional, descriptive analysis of a cohort of 100 patients with newly diagnosed MM. The patients were prospectively and consecutively included at two departments of haematology at two University Hospitals in Denmark from 22 June, 2015 to 18 January, 2019 as part of a randomised, controlled trial (ClinicalTrials.gov., ID NCT02439112) investigating the effect of a 10 week exercise intervention. Patients were screened for eligibility at time of diagnosis by the haematologist, based on inclusion and exclusion criteria. Introductory information about the study was given, and afterwards the principal investigator contacted the patient to give further information and for final inclusion. Included were patients $\geq 18$ years of age newly diagnosed with treatment demanding MM (High Dose Therapy with Stem Cell Transplantation (HDT-SCT) or less intensive treatment), and who were able to speak and understand Danish. Exclusion criteria were spinal cord compression, unstable vertebral fracture (Spinal Instability Neoplastic Score > 12) [23], untreated cardiac failure or untreated cardiac arrhythmia, severe chronic cardiac failure (NYHA 3-4), other severe comorbidity that according to treating physician would not permit physical exercise, and psychological or psychiatric disorders. Written informed consent are obtained from all individual participants included in the study.

\section{Data collection}

Prior to start of the treatment in an outpatient setting, all eligible patients were tested with the following physical function measurements: Six-Minute-Walk-Test (6MWT) [24] as a functional measure of aerobic capacity, Sit-to-Stand-Test (SST) [25] as a functional measure of lower body strength, grip strength $[26,27]$ as a measure of upper body strength and a direct measure of isometric knee extension strength [27, 28]. Prior to testing, the haematologist performed a systematic assessment of the impact of the radiologically assessed bone disease to determine restrictions regarding the physical tests (and exercise as well, to be used in the randomised controlled trial). In relation to testing, our focus was on the femoral bone. The assessment captured size of osteolytic lesions, fractures, and if applicable, estimated the time of fractures, and the haematologist assessed the degree of pain. Based on Mirel's scoring system [29], this combined information of location, fractures/size of lesions and pain were used to assess whether the fractures and/or bone destructions should restrict certain tests. That was the case if an osteolytic lesion in the femoral bone involved between one third and up to two thirds of the diameter and caused pain, or if an osteolytic lesion involved more than two thirds of the diameter or involved the cortical bone (cortical thinning), even without associated pain. In these cases we only tested the unaffected side and omitted SST. 
The physical function data (6MWT, SST, grip strength and knee extension strength) used in the current analysis are data from the baseline measures in the randomised controlled trial (ClinicalTrials.gov, ID NCT02439112), conducted by a project team of trained physiotherapists. Patient demographic and medical characteristics were collected from the patients' medical records. The testing of 6MWT, SST and grip strength followed guidelines [25, 27, 30-33], while the knee extension strength was measured by a standardised protocol developed for the randomised controlled trial. It was measured by a dynamometer (Lafayette Manual Muscle Tester), which was perpendicularly fixated to a bench by a strap. The participant was sitting on the bench with hip and knee flexion of $90^{\circ}$ and arms resting on the side. Then the strap with the dynamometer was placed around the participant's lower leg. The lower border of the dynamometer was placed five centimeters from the top of the lateral malleolus. The patient had three measures of right and left side, respectively regarding grip strength (until maximum value) and knee extension strength (each try was $5 \mathrm{~s}$ ). The highest value was used for the analysis.

We included normative data of physical function outcomes from different healthy populations [34-36] and published data from other cancer disease populations; malignant lymphoma before starting chemotherapy and without bone metastasis or elevated risk of fracture [37], prostate cancer after surgery or radiotherapy $[38,39]$ and breast cancer post-treatment $[40,41]$. These cancers were chosen to compare MM data to other haematological cancers, both malignant lymphoma without bone destructions, and solid cancers where bone destructions are common. Comparison with other haematological cancers is relevant, because typically patients with MM represent a minor part of the included patients in exercise studies in haematological cancer populations, and therefore it is unknown if they differ and should be approached separately or with a special focus. The two non-haematological cancer diagnoses (prostate cancer and breast cancer) are the most common gender specific diagnoses and both cancer types share an issue of bone health, bone destructions and bone pain [42]. In the following our study population is called the EMMY population (Exercise in Multiple MYeloma).

\section{Statistical analyses}

Characteristics of the cohort are reported as counts and proportions and stratified by gender. The physical outcome measures 6MWT, SST, grip strength and knee extension strength are reported as mean and standard deviation (SD) and stratified by gender and age groups. Data are compared by z-test (after standardisation to mean $=0$ and $S D=1$ ) to reference values from normative populations and furthermore, to published data from patients with malignant lymphoma, prostate cancer and breast cancer, respectively. Moreover, we present outcome measures as box plots stratified by bone involvement and fractures and compare the standardised measurements by Wilcoxon rank sum test. Sample size calculation showed that by inclusion of 100 patients, differences of $0.33 \mathrm{SD}$ with $90 \%$ power in the age- and gender-standardised outcome measures, compared to the reference populations, could be detected.

\section{Results}

In the randomised controlled trial, 158 patients were screened for eligibility. Out of the 158 patients, 33 were excluded because they did not meet the inclusion criteria, and 24 declined to participate. One patient accepted, but withdrew and did not give consent to use data. Thereby, the study cohort consisted of 100 participants. Demographic and medical characteristics are presented in Table 1.

Mean age (SD) was 67.7 (10.3) years, median (range) was 69 (38-90) years. The age group with the highest representation was $70-79$ years (35\%), followed by the age group 60-69 years (28\%). The major part of the patients $(85 \%)$ had an ECOG performance status of $0-1$. According to the Revised International Staging System (R-ISS), the patients separated into R-ISS1 in $21 \%$, RISS2 in 49\%, and R-ISS3 in 30\%. Comorbidities were rare and mild. Seventeen \% were using walking aids. Over half were retired (56\%), and $14 \%$ were on sick leave. Bone disease was present in $73 \%$ of the participants, and in three participants this caused restriction in testing (SST and unilateral knee extension strength) due to femoral bone involvement. Thirty-three per cent had fractures $(n=33)$. Hereof most common were vertebral fractures $(73 \%)$ resulting in mild pain $(17 \%)$, moderate pain (33\%), and functional pain (29\%). Nine per cent had non-vertebral fractures with associated pain that followed the same patterns as the vertebral fractures. In total, 55\% used pain relieving medications (31\% nonopioid drugs (mild), 11\% opioid drugs but less or maximum equivalent to $20 \mathrm{mg}$ morphine per day (moderate), and $13 \%$ opioid drugs equivalent to more than $20 \mathrm{mg}$ morphine per day (strong)).

Patients who did not meet the inclusion criteria $(n=$ 33 ), or fulfilled the inclusion criteria but did not wish to participate $(n=24)$ had a similar mean age as the included patients (68.4 years (SD 9.4) and 70.1 years (SD 7.8 ), respectively), and gender was similar as well (58 and $54 \%$ were males, respectively). Around two thirds (67\%) of the non-eligible patients and one third (38\%) of the patients who did not wish to participate, were screened during hospitalisation. The major part, $94 \%$ of the non-eligible patients and $79 \%$ of the patients who 
Table 1 Patient demographics in the total study population and according to gender

\begin{tabular}{|c|c|c|c|}
\hline Patient characteristics & $\begin{array}{l}\text { Total } \\
N=100\end{array}$ & $\begin{array}{l}\text { Male } \\
n=58\end{array}$ & $\begin{array}{l}\text { Female } \\
n=42\end{array}$ \\
\hline \multicolumn{4}{|l|}{ Age, years } \\
\hline Mean (SD) & $67.7(10.3)$ & $68.1(10.7)$ & $67.1(9.8)$ \\
\hline Median (range) & $69(38-90)$ & $70(38-89)$ & $67.5(49-$ \\
\hline \multicolumn{4}{|l|}{ Age groups, years (n (\%)) } \\
\hline$\leq 39$ & $1(1)$ & $1(2)$ & $0(0)$ \\
\hline $40-49$ & $3(3)$ & $1(2)$ & $2(5)$ \\
\hline $50-59$ & $20(20)$ & $11(19)$ & $9(21)$ \\
\hline $60-69$ & $28(28)$ & $15(26)$ & $13(31)$ \\
\hline $70-79$ & $35(35)$ & $22(38)$ & $13(31)$ \\
\hline $80-89$ & $12(12)$ & $8(14)$ & $4(10)$ \\
\hline$\geq 90$ & $1(1)$ & $0(0)$ & $1(2)$ \\
\hline \multicolumn{4}{|l|}{$\begin{array}{l}\text { ECOG performance } \\
\operatorname{status}^{\mathrm{a}}(n(\%))\end{array}$} \\
\hline $0-1$ & $85(85)$ & $46(79)$ & $39(93)$ \\
\hline$\geq 2$ & $15(15)$ & $12(21)$ & $3(7)$ \\
\hline \multicolumn{4}{|l|}{ R-ISS $(n(\%))^{\mathrm{b}}$} \\
\hline 1 & $21(21)$ & $9(16)$ & $12(29)$ \\
\hline 2 & $49(49)$ & $31(53)$ & $18(43)$ \\
\hline 3 & $30(30)$ & $18(31)$ & $12(29)$ \\
\hline \multicolumn{4}{|l|}{ Co-morbidity } \\
\hline Ischaemic heart disease & $6(6)$ & $6(10)$ & 0 \\
\hline Incompensated heart disease & $6(6)$ & $6(10)$ & 0 \\
\hline COL/chronic lung disease & $3(3)$ & $3(5)$ & 0 \\
\hline Asthma & 0 & 0 & 0 \\
\hline Rheumatoid arthritis & $1(1)$ & 0 & $1(2)$ \\
\hline Osteoarthritis & $7(7)$ & $6(10)$ & $1(2)$ \\
\hline Apoplexia/neurological disease & $6(6)$ & $6(10)$ & 0 \\
\hline Other & $13(13)$ & $7(12)$ & $6(14)$ \\
\hline Bone disease & $73(73)$ & $44(76)$ & $29(69)$ \\
\hline $\begin{array}{l}\text { Bone disease with restriction } \\
\text { for tests or exercise } e^{c}\end{array}$ & $41(41)^{e}$ & $23(40)$ & $18(43)$ \\
\hline Fracture $(n(\%))$ & $33(33)$ & $19(33)$ & $14(33)$ \\
\hline Non-vertebral fracture $(n(\%))$ & $9(9)$ & $3(5)$ & $6(14)$ \\
\hline Vertebral fracture $(n(\%))$ & $24(24)$ & $16(28)$ & $8(19)$ \\
\hline $\begin{array}{l}\text { Pain from non-vertebral fracture } \\
(n=9)\end{array}$ & $5(55)$ & 0 & $5(83)$ \\
\hline Mild & $2(22)$ & 0 & $2(33)$ \\
\hline Moderate & $1(11)$ & 0 & $1(17)$ \\
\hline Functional & $2(22)$ & 0 & $2(33)$ \\
\hline $\begin{array}{l}\text { Pain form vertebral fracture }(n= \\
\text { 24) }\end{array}$ & $19(79)$ & $13(81)$ & $6(75)$ \\
\hline Mild & $4(17)$ & $2(13)$ & $2(25)$ \\
\hline Moderate & $8(33)$ & $7(44)$ & $1(13)$ \\
\hline Functional & 7 (29) & $4(25)$ & $3(38)$ \\
\hline
\end{tabular}

Table 1 Patient demographics in the total study population and according to gender (Continued)

\begin{tabular}{|c|c|c|c|}
\hline Patient characteristics & $\begin{array}{l}\text { Total } \\
N=100\end{array}$ & $\begin{array}{l}\text { Male } \\
n=58\end{array}$ & $\begin{array}{l}\text { Female } \\
n=42\end{array}$ \\
\hline \multicolumn{4}{|l|}{ Pain relieving drugs ( $n(\%)$ ) } \\
\hline None & $45(45)$ & $28(48)$ & $17(40)$ \\
\hline $\begin{array}{l}\text { Non-opid/mildly pain relieving } \\
\text { drugs }^{d}\end{array}$ & $31(31)$ & $14(24)$ & $17(40)$ \\
\hline $\begin{array}{l}\text { Moderately pain relieving } \\
\text { drugs }^{\mathrm{e}}\end{array}$ & $11(11)$ & $6(10)$ & $5(12)$ \\
\hline Strong pain relieving drugs ${ }^{f}$ & $13(13)$ & $10(17)$ & $3(7)$ \\
\hline \multicolumn{4}{|l|}{ Walking aid (n (\%)) } \\
\hline Yes & $17(17)$ & $9(16)$ & $8(19)$ \\
\hline No & $81(81)$ & $47(81)$ & $34(81)$ \\
\hline Missing & $2(2)$ & $2(3)$ & $0(0)$ \\
\hline \multicolumn{4}{|l|}{ Working (n (\%)) } \\
\hline Yes & $20(20)$ & $16(28)$ & $4(10)$ \\
\hline No & $78(78)$ & $40(69)$ & $38(90)$ \\
\hline Missing & $2(2)$ & $2(3)$ & $0(0)$ \\
\hline \multicolumn{4}{|l|}{ Working status (n (\%)) } \\
\hline Working & $20(20)$ & $16(28)$ & $4(10)$ \\
\hline Retired & $56(56)$ & $29(50)$ & $27(64)$ \\
\hline Early retirement & $3(3)$ & $1(2)$ & $2(5)$ \\
\hline Off work sick, full time & $14(14)$ & $8(14)$ & $6(14)$ \\
\hline Un-employed & $1(1)$ & $0(0)$ & $1(2)$ \\
\hline On social security & $1(1)$ & $0(0)$ & $1(2)$ \\
\hline Other reason & $2(2)$ & $1(2)$ & $1(2)$ \\
\hline Missing & $3(3)$ & $3(5)$ & $0(0)$ \\
\hline
\end{tabular}

${ }^{a}$ ECOG Eastern Cooperative Oncology Group. ${ }^{\mathrm{b}} \mathrm{R}-\mathrm{ISS}$ Revised International Staging System. ' three participants had restrictions for the test part. ${ }^{d}$ nonopioid drugs. eopioid drugs but less or maximum equivalent to $20 \mathrm{mg}$ morphine per day. ${ }^{\text {ef }}$ opioid drugs equivalent to more than $20 \mathrm{mg}$ morphine per day

did not wish to participate, had bone disease, which is slightly more than patients in the study cohort.

The physical function measurement data are presented in Figs. 1a-d and 2a-d, and the specific estimates (mean (SD)) for the four outcome measures are presented in Table 2. Box plots for the four physical measures according to bone disease, fracture and vertebral fracture are presented in Fig. 3.

\section{Six-minute-walk-test (6MWT)}

All mean scores, regardless of gender, were lower than for the normal population [34] and furthermore, all mean scores were below the lower SD-reference line for the normal population (Fig. $1 \mathrm{a}$ and $\mathrm{b}$ ). The difference between EMMY and the reference population was statistically significant $(p<0.0001, \quad z$-score -1.25$)$. The $6 \mathrm{MWT}$ measurement was neither modified by the presence of vertebral fracture $(p=0.061)$, bone disease $(p=$ 
a.

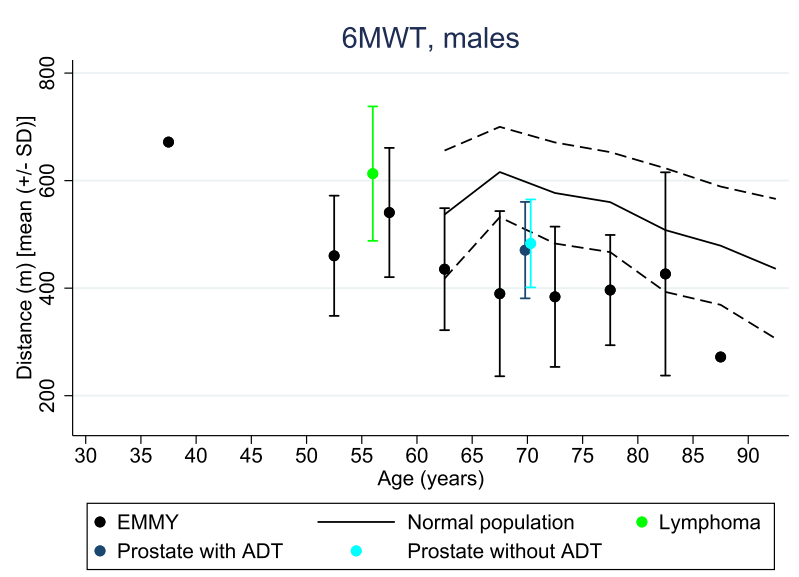

c.

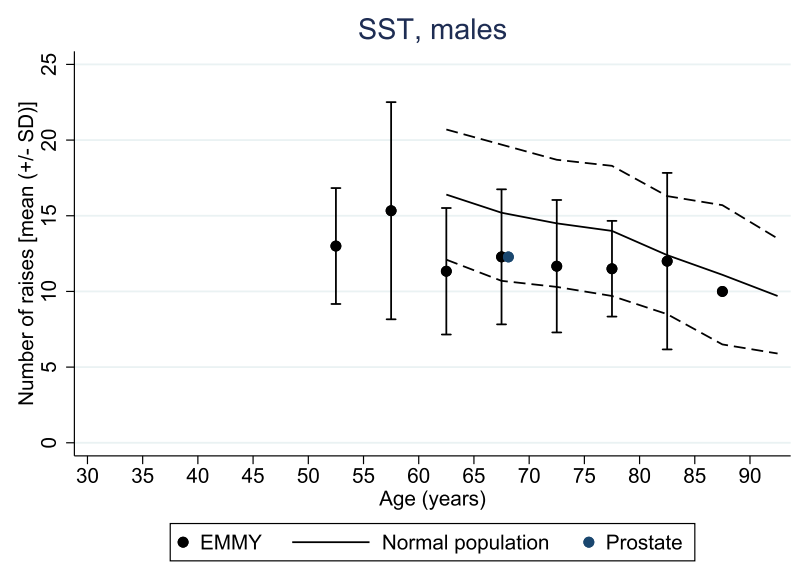

b.

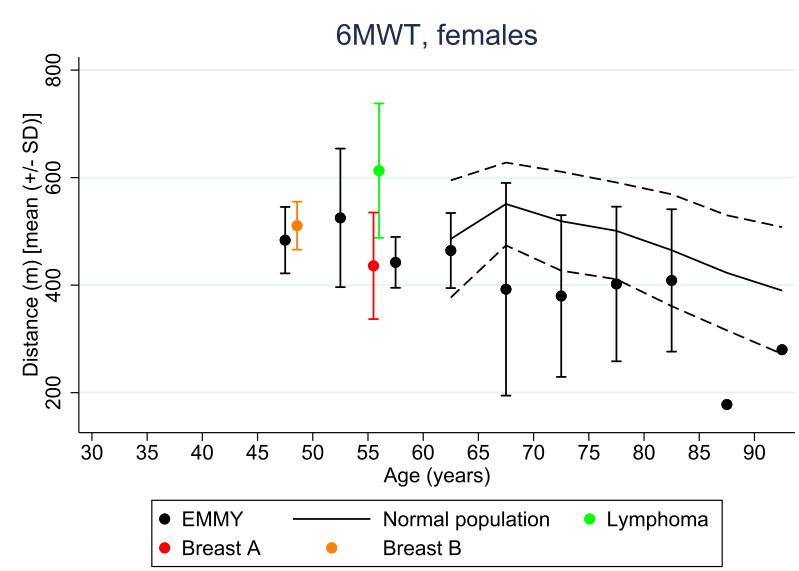

d.

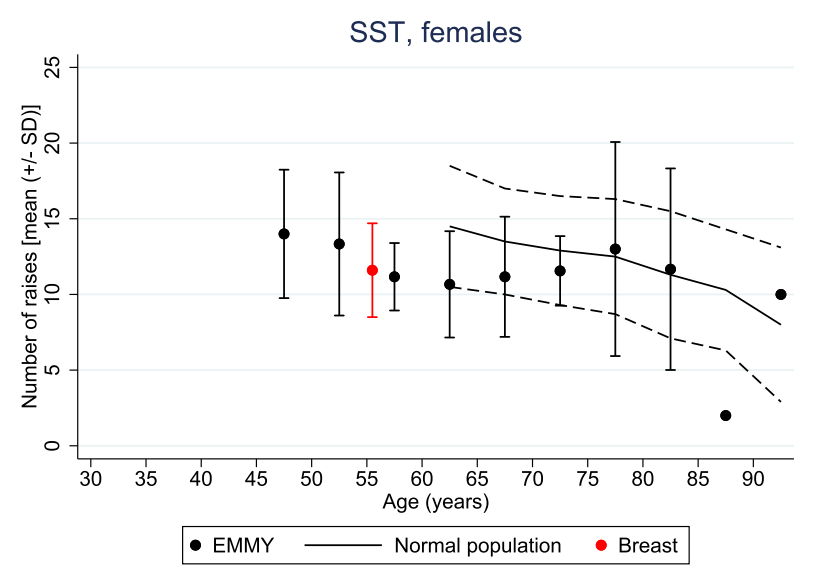

Fig. 1 a-d Age group and gender specific Six-Minute-Walk-Test and Sit-to-Stand-Test in EMMY population, normal population, and cancer populations. a Normal [34]. Lymphoma [37], Prostate (+/- ADT) [38]. b Normal [34]. Lymphoma [37], Breast A [40]. Breast B [41]. c Normal population [34]. Prostate [39]. d Normal population [34]. Breast [40]. EMMY data are illustrated by means and SD-bars (within the 5 year intervals) and reference values from the normal populations are illustrated by curves (full line indicates mean and dotted lines are +/- SD)

0.657) nor fracture $(p=0.758)$ (Fig. 3). Compared to lymphoma cancer (mixed genders) aged 55-59 years [37], the EMMY population had a shorter walking distance with a mean difference of $73 \mathrm{~m}$ and $171 \mathrm{~m}$ for males and females, respectively (Fig. 1a and b). Males with prostate cancer aged 70-74 years [38] achieved a longer walking distance than the EMMY population (Fig. 1a). Females with breast cancer aged 55-60 years [40] had a shorter walking distance than females from the EMMY population (Fig. 1b, Breast B), but younger females with breast cancer (approximately 47 years) [41] had almost the same walking distance as females from the EMMY population (Fig. 1b, Breast A).

\section{Sit-to-stand-test (SST)}

Compared to the normal population [34], males between 60 and 80 years (Fig. 1c) and females between 60 and 75 years (Fig. 1d) had a lower number of mean raises. The total EMMY population (males and females) had statistically significantly lower mean raises than the reference group $(p<0.0001$, z-score -0.55$)$, and number of mean raises was modified by the presence of bone involvement $(p=0.033)$ or fracture $(p=0.044)$, but not by vertebral fracture $(p=0.058)$ (Fig. 3). Comparing SST scores for males from the EMMY population to males with prostate cancer within the age group 65-70 years [39] or to females with breast cancer [40] the number of raises was almost identical.

\section{Grip strength}

Grip strength (mean (SD)) in the total group was statistically significantly higher than in the normal population [35] (Fig. 2a and b) ( $p<0.00001$, z-score 0.49) and modified by the presence of fracture $(p=0.025)$ or vertebral fracture $(p=0.005)$, but not bone involvement $(p=$ 0.261) (Fig. 3). Compared to the population with 

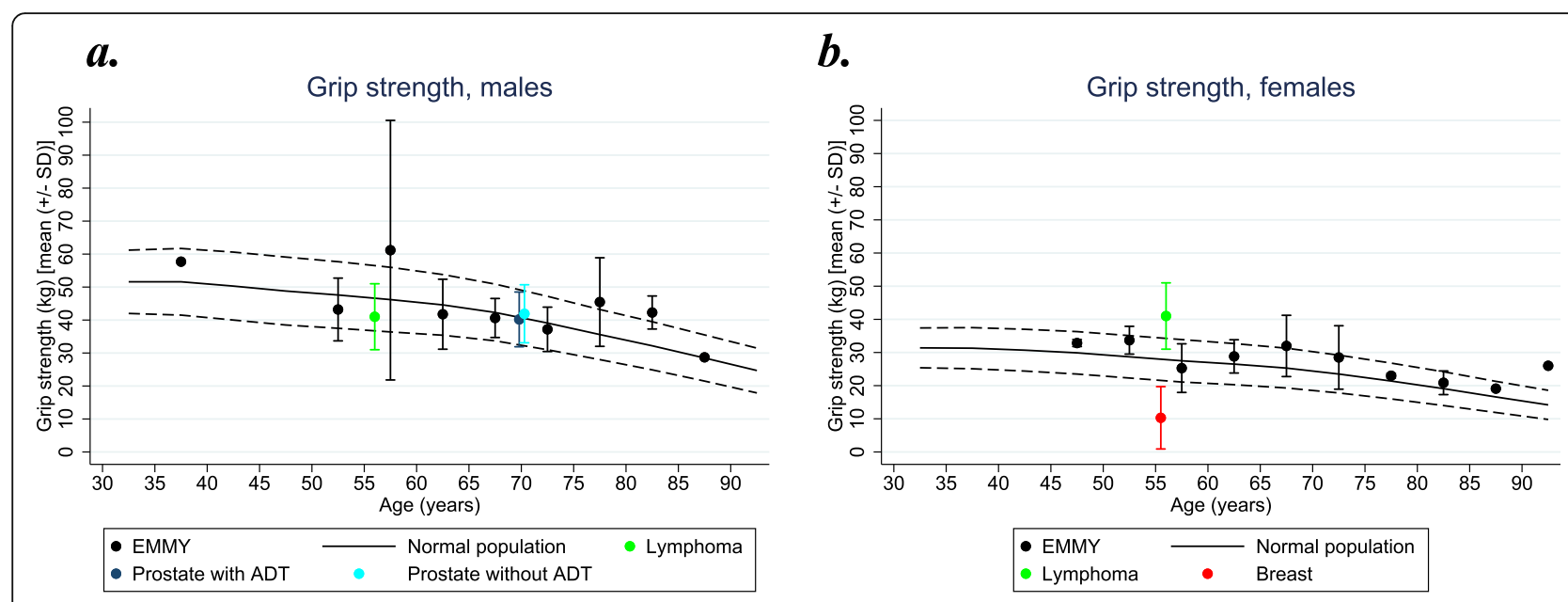

c.

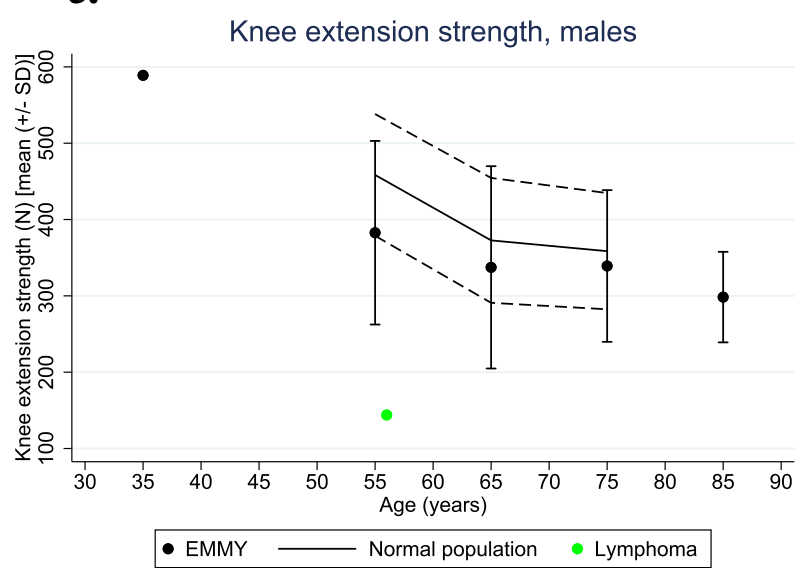

d.

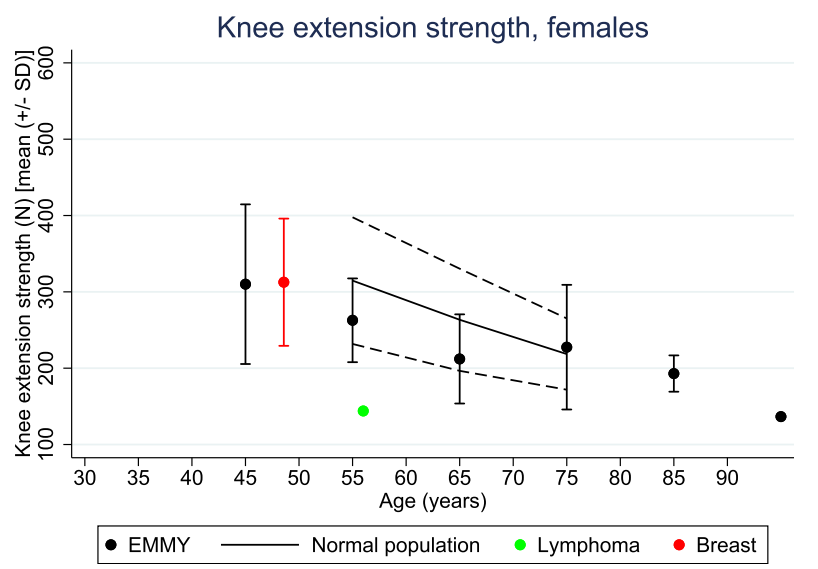

Fig. $\mathbf{2}$ a-d Age group and gender specific grip and knee extension strength in EMMY population, normal population, and cancer populations. a Normal [35]. Lymphoma [37], Prostate (+/- ADT) [38]. b Normal [35]. Lymphoma [37]. Breast [40]. c Normal [36]. Lymphoma [37]. d Normal [36]. Lymphoma [37]. Breast [41]. EMMY data are illustrated by means and SD-bars (within the 5 years intervals for grip strength and 10 year intervals for knee extension strength) and reference values from the normal population are illustrated by curves (full line indicates mean and dotted lines indicate +/- SD)

lymphoma (mixed group of gender), the females from the EMMY population scored lower than the population with lymphoma cancer, while males had almost the same grip strength [37]. Though, this must be with reservations of comparing a mixed group of gender with females and males, respectively. For males with prostate cancer [38] there was no difference in mean grip strength compared to the EMMY population. Females with breast cancer [40] had a lower grip strength than the EMMY population.

\section{Knee extension strength}

Within the different age groups, the EMMY population (both genders) generally had lower strength compared to the normal population [36] (Fig. 2c and d). For the total group this difference was statistically significant $(p=$ $0.0005, \mathrm{z}$-score -0.39 ) and not modified by the presence of bone involvement $(p=0.246)$, fracture $(p=0.792)$ or vertebral fracture $(p=0.543)$ (Fig. 3). The lymphoma population [37] had much lower strength than the EMMY population. Females with breast cancer [41] and the patients from the EMMY population had almost the same strength in the age span $40-50$ years.

\section{Discussion}

The aim of this study was to describe age and gender specific physical function among patients newly diagnosed with multiple myeloma and to compare physical function to healthy populations and other cancer populations.

We found that the EMMY population had poorer physical function than the normal population, though unexpectedly, grip strength was found to be better in patients with MM. The presence of bone involvement and fractures modified SST and grip strength (fractures only) 
Table 2 Estimates (mean (SD)) for Six-Minute-Walk-Test, Sit-to-Stand-Test, grip and knee extension strength

\begin{tabular}{|c|c|c|c|c|c|c|c|c|c|}
\hline \multirow[t]{2}{*}{ Gender } & \multirow[t]{2}{*}{$\begin{array}{l}\text { Age } \\
\text { group }\end{array}$} & \multicolumn{2}{|c|}{$\begin{array}{l}\text { 6MWT } \\
\text { (distance in meters) }\end{array}$} & \multicolumn{2}{|c|}{$\begin{array}{l}\text { SST } \\
\text { (number of raises) }\end{array}$} & \multicolumn{2}{|c|}{$\begin{array}{l}\text { Grip strength } \\
\text { (kilograms) }\end{array}$} & \multicolumn{2}{|c|}{ Knee extension strength (Newton) } \\
\hline & & $\mathrm{N}$ & Mean (SD) & $\mathrm{N}$ & Mean (SD) & $\mathrm{N}$ & Mean (SD) & $\mathrm{N}$ & Mean (SD) \\
\hline \multirow[t]{12}{*}{ Males $(n=58)$} & $35-39$ & 1 & $671.75()$. & 0 & & 1 & $57.70()$. & 1 & $588.90()$. \\
\hline & $40-44$ & 0 & & 0 & & 0 & & 0 & \\
\hline & $45-49$ & 0 & & 0 & & 0 & & & \\
\hline & $50-54$ & 5 & $460.24(111.79)$ & 4 & $13.00(3.83)$ & 5 & $43.20(9.51)$ & 11 & $382.71(120.27)$ \\
\hline & $55-59$ & 6 & $540.68(120.18)$ & 6 & $15.33(7.17)$ & 6 & $61.18(39.35)$ & & \\
\hline & $60-64$ & 6 & $435.32(113.46)$ & 6 & $11.33(4.18)$ & 6 & $41.77(10.61)$ & 13 & $337.37(132.51)$ \\
\hline & $65-69$ & 9 & $389.74(153.62)$ & 7 & $12.29(4.46)$ & 9 & $40.62(5.92)$ & & \\
\hline & $70-74$ & 12 & 383.96 (130.49) & 12 & $11.67(4.38)$ & 13 & 37.18 (6.73) & 21 & 339.16 (99.37) \\
\hline & $75-79$ & 9 & $396.43(102.51)$ & 8 & $11.50(3.16)$ & 9 & $45.46(13.43)$ & & \\
\hline & $80-84$ & 6 & $426.44(189.02)$ & 6 & $12.00(5.83)$ & 6 & $42.28(5.01)$ & 7 & 298.39 (59.32) \\
\hline & $85-89$ & 1 & $272.00()$. & 1 & $10.00()$. & 1 & $28.70()$. & & \\
\hline & $90+$ & 0 & & 0 & & 0 & & 0 & \\
\hline \multirow[t]{12}{*}{ Females $(n=42)$} & $35-39$ & 0 & & 0 & & 0 & & 0 & \\
\hline & $40-44$ & 0 & & 0 & & 0 & & 2 & 310.05 (104.58) \\
\hline & $45-49$ & 2 & $483.68(61.77)$ & 2 & $14.00(4.24)$ & 2 & $32.85(1.06)$ & & \\
\hline & $50-54$ & 3 & $525.17(128.83)$ & 3 & $13.33(4.73)$ & 3 & $33.70(4.19)$ & 9 & $262.76(54.87)$ \\
\hline & $55-59$ & 6 & $442.35(47.28)$ & 6 & $11.17(2.23)$ & 6 & $25.28(7.33)$ & & \\
\hline & $60-64$ & 4 & 464.40 (69.78) & 3 & $10.67(3.51)$ & 4 & $28.83(5.02)$ & 10 & $212.13(58.41)$ \\
\hline & $65-69$ & 8 & 392.34 (197.78) & 6 & 11.17 (3.97) & 9 & $31.98(9.24)$ & & \\
\hline & $70-74$ & 11 & $379.78(150.43)$ & 9 & $11.56(2.30)$ & 11 & $28.50(9.57)$ & 12 & 227.53 (81.65) \\
\hline & $75-79$ & 2 & $402.18(143.80)$ & 2 & $13.00(7.07)$ & 2 & $23.00(0.71)$ & & \\
\hline & $80-84$ & 3 & 408.77 (132.39) & 3 & $11.67(6.66)$ & 3 & $20.87(3.57)$ & 4 & 192.98 (23.79) \\
\hline & $85-89$ & 1 & $178.02()$. & 1 & $2.00()$. & 1 & $19.10()$. & & \\
\hline & $90+$ & 1 & $280.00()$. & 1 & $10.00()$. & 1 & $26.00()$. & 1 & $136.60()$. \\
\hline Missing (total) & & $4^{a}$ & & $14^{\mathrm{b}}$ & & $2^{c}$ & & $9^{d}$ & \\
\hline
\end{tabular}

Note: Knee extension strength is reported in 10 year age groups. SD cannot be estimated, if only one observation

${ }^{a}$ Missing data of 6MWT were caused by pain $(n=1)$, sudden impairment $(n=2)$, unknown $(n=1)$

${ }^{\mathrm{b}}$ Missing data of SST were caused by restriction $(n=3)$, pain $(n=2)$, sudden impairment $(n=2)$, personal failure/misunderstanding $(n=4)$, unknown $(n=3)$

${ }^{c}$ Missing data of grip strength were caused by sudden impairment $(n=2)$

${ }^{\mathrm{d}}$ Missing data of knee extension strength were caused by pain $(n=1)$, restriction $(n=1)$, sudden impairment $(n=2)$, apparatus failure ( $\left.n=1\right)$, personal failure/ misunderstanding $(n=2)$, unknown $(n=4)$

and the presence of vertebral fracture marginally modified the 6MWT. In the three cancer comparison groups, we found the patients with lymphoma to have better aerobic capacity, but lower strength in the lower extremities, whereas we did not observe differences compared to the prostate cancer and breast cancer groups, except grip strength, which was better in patients with MM.

Generally, the EMMY population did not follow a clear age-decline pattern. A possible explanation could be that the younger patients (from around 60 years up to 70 years) with $\mathrm{MM}$ are more vulnerable to the disease, resulting in affected physical function, than those under the age of 60 and over 70 years, regardless of gender. However, we need to take the number of patients in the EMMY population in each age span into consideration, which means that the uncertainty becomes wider in the younger and older ages. Most patients (63\%) were within the ages of 60-79 years. Another explanation could be the confounding factors (bone involvement, fracture or vertebral fracture), which are not related to age. There is no obvious explanation for the better performance in grip strength in the EMMY population compared to the normal population. Possible explanations could be changes in general movement or use of one's body caused by pain.

Knee extension strength in patients with lymphoma [37] was below the knee extension strength in patients with MM, and accordingly, the grip strength in patients with breast cancer [40] was below the grip strength in patients with MM. According to the authors, the poor 


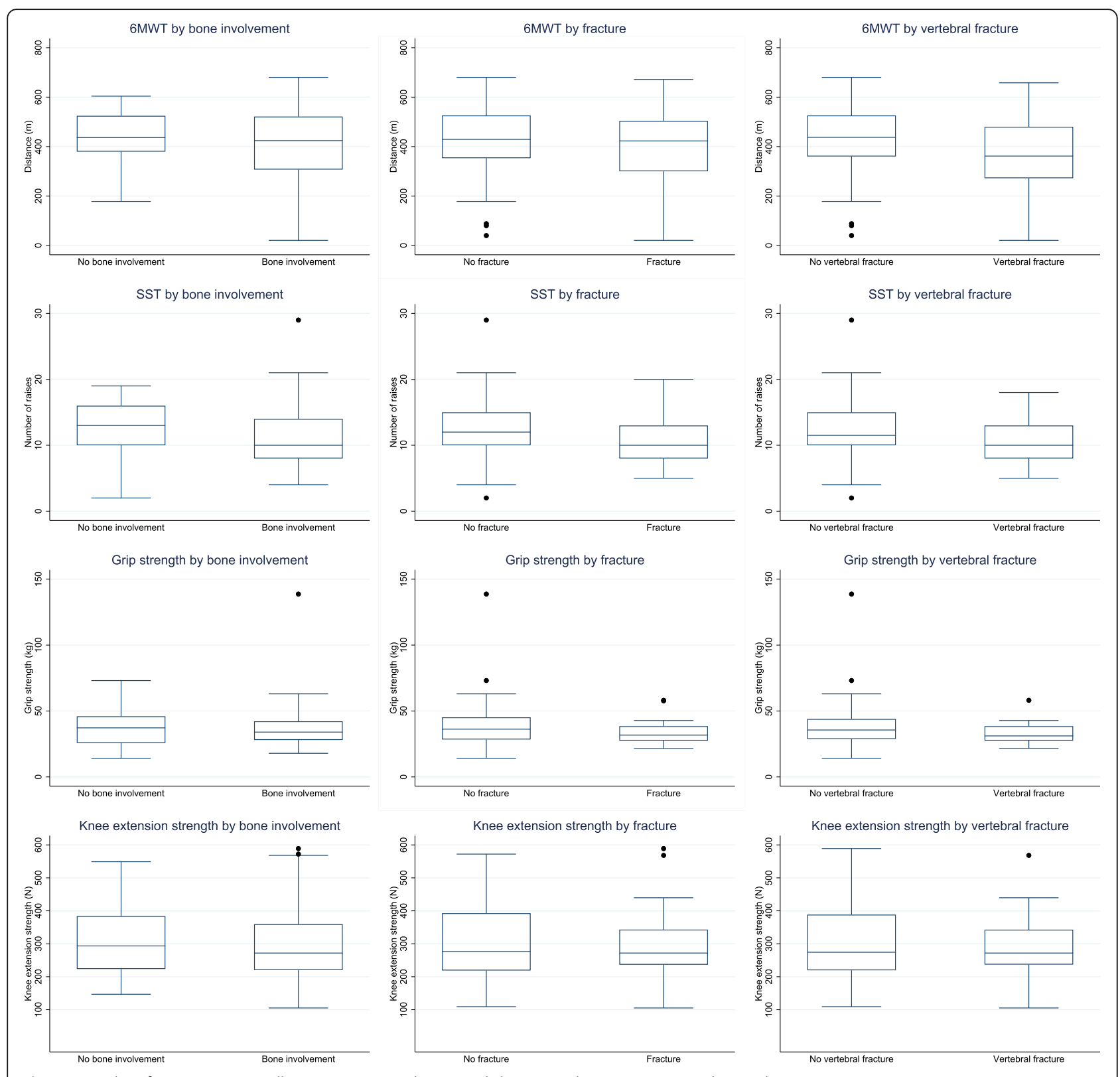

Fig. 3 Box plots for Six-Minute-Walk-Test, Sit-to-Stand-Test, and the strength measures according to bone status

knee extension strength might be explained by the disease itself, weight loss as part of B-symptoms, including enhanced protein catabolism, and upregulated tumor necrosis factor stimulating muscle wasting and causing contractile dysfunction [37]. B-symptoms are not common in MM (3). However, it should be added that another study of a mixed group of patients with lymphoma and MM [43] (mean age of 55 years, range 19-67) did not find poorer muscle strength in lower extremities measured by SST [43] compared to the EMMY population.

The poorer grip strength among patients with breast cancer is an expected finding because of disease location and treatment side effects. Further, a study showed that reduced grip strength was not restricted to the affected side [44]. A hypothesis could be that patients with breast cancer generally protect their upper extremities and thus, are losing grip strength. This is underpinned by the comparable results of knee extension strength and SST, respectively between the EMMY population and the breast cancer population. Thus, there does not seem to be a general muscle strength problem among patients with breast cancer.

Patients with lymphoma performed better in the 6MWT compared to patients with MM. In the study by Persoon et al. [43] investigating health-related physical 
fitness after HDT-SCT, they included patients with MM and patients with lymphoma. Unfortunately, they did not present physical outcome results for the two diagnoses separately, which could either have supported or rejected our interpretation of strength as a challenge for patients with lymphoma and aerobic capacity as a challenge for patients with MM.

\section{Validity}

The Danish test procedure for 6MWT (used in our study) [45] is in accordance with the American Thoracic Society test procedure [24], but Rikli et al. [34] deviated from that procedure regarding instruction to the patient. In the ATS test procedure patients are encouraged to walk as far as possible and are told that they will experience exertion [24], while Rikli et al. [34] told them to walk the best they could, but to avoid pushing themselves to overexertion or beyond what they thought would be safe for them.

Potentially, this could have the consequence that the reference values could be higher, if Rikli et al. [34] had followed the ATS procedure. Thus, the 6MWT difference between the patients with MM compared to reference values may be underestimated. Overall, the test position in the knee extension strength measure does not differ from the one used in the EMMY population. There is a difference regarding grip strength (using sitting or standing position) in the review [35], but the authors conclude that the different positions do not affect grip strength. We assume, that SST is very standardised, and thus does not differ between studies.

\section{Methods considerations, strengths and limitations}

In the field of MM and physical function, the size of our cohort is quite large, and essential characteristics such as age, gender and bone disease are in accordance with the expected in the general MM population [3]. The R-ISS scores were according to the expected [46], although a bit higher proportion (30\%) of our participants had RISS 3 , which probably reflects that our cohort is population based and thereby included more patients with high Beta-2-microglobulin due to renal insufficiency than are observed in randomized clinical trials, because these patients do not fulfil inclusion/exclusion criteria [46]. Comorbidities were rare and mild, probably reflecting that included participants should be able to perform exercise training without being hampered by comorbid condition. Exclusion of patients with comorbidities may have been the physician's decision as well as the patient's choice of non-participation. We are not able to provide exact data on that. However, as a consequence, our data reflect the impact of MM and not comorbidities. Though, we have missing data, only a minor part was due to bone disease in the femoral bone ( $n=3$ for the SST). Thus, we believe our study and findings are representative for patients with $\mathrm{MM}$ in everyday clinical practice and thereby heighten the external validity of our study.

The associations between physical function and bone disease or fracture, indicate that these subgroups need special attention in a physical function perspective.

It is a strength that we have age specific data from normal samples, but regarding age-specific comparisons, when divided into age groups we are hampered by a rather small number of participants, especially in the lower and upper age groups.

There are some shortcomings in the comparisons, since we were unable to cover the total age span of the EMMY population in the comparisons with the normal population as well as comparisons with other cancer disease populations. We do not have data from citizens under the age of 60 years for 6MWT and SST, and under the age of 55 years for the knee extension strength. However, we assume that the association between age and physical performance will follow the same pattern for the younger age groups ( $<60$ years) [47], at least, according to the literature, for the walking distance $[48,49]$ and grip strength [47]. Furthermore, we did not have data on all the needed physical outcomes in the cancer disease populations. Finally, we need to address that the EMMY data are at time of diagnosis, which is different from the time points in the other cancer population studies, except for the lymphoma population. The differences in time points, and settings as well could influence the external validity.

\section{Implications for practice and future perspectives}

Generally, our results indicate, that patients with MM have lower physical function at time of diagnosis and that this particularly is the case for patients with bone involvement. After start of anti-myeloma treatment, physical function may worsen, but we lack strong data on this. Bone studies in MM have shown that early bone fractures are common within the first weeks and observed in about $15 \%$ within 3 months [50]. This is assumed to cause deterioration of physical function. Patients undergoing HDT-SCT can experience loss in function during treatment. Potentially, such loss can be prevented or minimised by exercise [51] as shown in exercise studies among other cancer populations [19] and among elderly [20], although little is known about exercise interventions at time of diagnosis [52, 53] . Other treatments than HDT-SCT, typically offered to patients over the age of 65-70 years, are less intensive, but still may affect the physical function as well. Since the patients are older and may be frail [54] early detection of physical decline and subsequent early prevention by providing exercise interventions is of importance.

Our study accommodates the gap of knowledge of physical function in newly diagnosed patients with MM. 
Although our cohort is relatively large, further research is needed if we want to establish evidence of the physical function limitations. This could have implications for clinical practice, either by identifying patients at risk at group or individual level, and then establish an exercise regimen aiming at preventing physical decline and thereby importantly maintaining independence and quality of life.

\section{Conclusions}

In this Danish cohort of newly diagnosed patients with MM, the patients have reduced physical function compared to the normal population, except for grip strength. In particular, bone disease and fractures influence the physical function.

\section{Abbreviations \\ 6MWT: Six-minute-Walk-Test; ECOG: Eastern Cooperative Oncology Group; EMMY: Exercise in Multiple MYeloma; HDT- SCT: High Dose Therapy with Stem Cell Transplantation; MM: Multiple Myeloma; SST: Sit-to-Stand-Test}

\section{Acknowledgements}

The authors thank the physiotherapists at Zealand University Hospital and Odense University Hospital for carrying out the outcome tests and supervising the exercise sessions. Special thanks to the physiotherapists Anders Hansen, Maria Thorning, Mette Dilby, Linda Susanne Rasmussen, Tine Ramskov Larsen, Marie Frøland, and Lars Bo Jørgensen for their assistance with project coordination for periods of time. Furthermore, we thank the medical doctors from both Departments of Haematology for conducting the screening and the nurses for assistance with coordination of study procedures. Finally, we thank all participating patients.

\section{Authors' contributions}

RFL designed the work, did the analyses and interpretation of data, and drafted the manuscript, made changes revision, and finalised the manuscript. MJ, LRM, UCF, and NA designed the work, contributed to analyses, interpretation of data, and revision of the manuscript. UCF and NA recruited participants. SM contributed to data analyses and interpretation of data, and revision of the manuscript. All authors approved the final manuscript.

\section{Funding}

This work was supported by: Zealand University Hospital; Region Zealand; Region of Southern Denmark; The Association of Danish Physiotherapists; The Academy of Geriatric Cancer Research (AgeCare) - Odense University Hospital; The Danish Knowledge Centre for Rehabilitation and Palliative Care (REHPA) - Odense University Hospital, Nyborg; and Amgen A/S, Denmark. The funders had no influence on study design; collection, management, analyses, or interpretation of data; or writing of the manuscript.

\section{Availability of data and materials}

The datasets used and/or analysed during the current study are available from the corresponding author on reasonable request.

\section{Ethics approval and consent to participate}

All procedures performed in studies involving human participants were in accordance with the ethical standards of the institutional and/or national research committee and with the 1964 Helsinki Declaration and its later amendments or comparable ethical standards. The study is approved by the Ethical Scientific Committee in Region Zealand (SJ-422), registered 11 December 2014 and by the Danish Data Protection Agency (REG-122-2014), registered 30 December 2014. Written informed consent are obtained from all individual participants included in the study.

\section{Consent for publication}

Not applicable.

\section{Competing interests}

The authors declare that they have no competing interests.

\section{Author details}

'Department of Physiotherapy and Occupational Therapy, Zealand University Hospital, Roskilde, Denmark. ${ }^{2}$ Department of Clinical Research, University of Southern Denmark, Odense, Denmark. ${ }^{3}$ OPEN, Open Patient data Explorative Network, Odense University Hospital, Odense, Denmark. ${ }^{4}$ Department of Haematology, Copenhagen University Hospital, Rigshospitalet, Copenhagen, Denmark. ${ }^{5}$ Department of Public Health, Faculty of Health and Medical Sciences, University of Copenhagen, Copenhagen, Denmark. ${ }^{6}$ Department of Rehabilitation, Odense University Hospital, Odense, Denmark. ${ }^{7}$ Health Science Research Centre, UCL University College, Odense, Denmark. ${ }^{8}$ Department of Haematology, Zealand University Hospital, Roskilde, Denmark. ${ }^{9}$ Department of Haematology, Odense University Hospital, Odense, Denmark. ${ }^{10}$ The Academy of Geriatric Cancer Research (AgeCare), Odense University Hospital, Odense, Denmark.

Received: 23 September 2019 Accepted: 17 February 2020

Published online: 03 March 2020

\section{References}

1. Liu RDKS, Chinapaw MJM, Huijgens PC, van Mechelen W. Physical exercise interventions in haematological cancer patients, feasible to conduct but effectiveness to be established: a systematic literature review. Cancer Treat Rev. 2009;35(2):185-92.

2. Jarden M. A systematic review of Nonpharmalogical exercise-based rehabilitative interventions in adults undergoing hematopoietic stem cell transplantation. In: Demirer T, editor. New advances in stem cell transplantation. Rijeka: InTech; 2012. p. 557-82.

3. Kyle RA, Gertz MA, Witzig TE, Lust JA, Lacy MQ, Dispenzieri A, et al. Review of 1027 patients with newly diagnosed multiple myeloma. Mayo Clin Proc. 2003;78(1):21-33.

4. Waage A, Gimsing P, Fayers P, Abildgaard N, Ahlberg L, Bjorkstrand B, et al. Melphalan and prednisone plus thalidomide or placebo in elderly patients with multiple myeloma. Blood. 2010;116(9):1405-12.

5. Delforge M, Dhawan R, Robinson D, Meunier J, Regnault A, Esseltine D-L, et al. Health-related quality of life in elderly, newly diagnosed multiple myeloma patients treated with VMP vs. MP: results from the VISTA trial. Eur J Haematol. 2012;89(1):16-27.

6. Delforge M, Minuk L, Eisenmann J-C, Arnulf B, Canepa L, Fragasso A, et al. Health-related quality-of-life in patients with newly diagnosed multiple myeloma in the FIRST trial: lenalidomide plus low-dose dexamethasone versus melphalan, prednisone, thalidomide. Haematologica. 2015;100(6):826-33.

7. Gimsing P, Carlson K, Turesson I, Fayers P, Waage A, Vangsted A, et al. Effect of pamidronate $30 \mathrm{mg}$ versus $90 \mathrm{mg}$ on physical function in patients with newly diagnosed multiple myeloma (Nordic myeloma study group): a double-blind, randomised controlled trial. Lancet Oncol. 2010;11(10):973-82.

8. Johnsen AT, Tholstrup D, Petersen MA, Pedersen L, Groenvold M. Health related quality of life in a nationally representative sample of haematological patients. Eur J Haematol. 2009:83(2):139-48.

9. Mols F, Oerlemans S, Vos AH, Koster A, Verelst S, Sonneveld P, et al. Healthrelated quality of life and disease-specific complaints among multiple myeloma patients up to $10 \mathrm{yr}$ after diagnosis: results from a populationbased study using the PROFILES registry. Eur J Haematol. 2012;89(4):311-9.

10. Gulbrandsen N, Wisløff F, Brinch L, Carlson K, Dahl IM, Gimsing P, et al. Health-related quality of life in multiple myeloma patients receiving highdose chemotherapy with autologous blood stem-cell support. Med Oncol. 2001;18:13.

11. Morey MC, Pieper CF, Cornoni-Huntley J. Physical fitness and functional limitations in community-dwelling older adults. Med Sci Sports Exerc. 1998; 30(5):715-23.

12. Rikli RE, Jones CJ. Development and validation of criterion-referenced clinically relevant fitness standards for maintaining physical Independence in later years. The Gerontologist. 2013;53(2):255-67.

13. Vermeulen J, Neyens JC, van Rossum E, Spreeuwenberg MD, de Witte LP. Predicting ADL disability in community-dwelling elderly people using physical frailty indicators: a systematic review. BMC Geriatr. 2011;11:33.

14. Bodilsen AC, Klausen HH, Petersen J, Beyer N, Andersen O, Jørgensen LM, et al. Prediction of Mobility Limitations after Hospitalization in Older Medical Patients by Simple Measures of Physical Performance Obtained at Admission to the Emergency Department. PLoS ONE. 2016;11(5):e0154350.

15. Cook G, Royle K-L, Pawlyn C, Hockaday A, Shah V, Kaiser MF, et al. A clinical prediction model for outcome and therapy delivery in transplant-ineligible 
patients with myeloma (UK myeloma research Alliance risk profile): a development and validation study. Lancet Haematol. 2019;6(3):e154-66.

16. Turesson I, Abildgaard N, Ahlgren T, Dahl I-M, Holmberg E, Hjorth M, et al. Prognostic evaluation in multiple myeloma: an analysis of the impact of new prognostic factors. Br J Haematol. 1999;106(4):1005-12.

17. Hall SA, Chiu GR, Williams RE, Clark RV, Araujo AB. Physical function and health-related quality-of-life in a population-based sample. Aging Male Off J Int Soc Study Aging Male. 2011;14(2):119-26.

18. Oh B, Cho B, Choi H-C, Son K-Y, Park SM, Chun S, et al. The influence of lower-extremity function in elderly individuals' quality of life (QOL): an analysis of the correlation between SPPB and EQ-5D. Arch Gerontol Geriatr. 2014;58(2):278-82.

19. Campbell K, Winters-Stone K, Wiskemann J, May A, Schwartz A, Courneya K, et al. Exercise guidelines for Cancer survivors: consensus statement from international multidisciplinary roundtable. Med Sci Sports Exerc. 2019;51(11):2375-90.

20. Liberman K, Forti LN, Beyer I, Bautmans I. The effects of exercise on muscle strength, body composition, physical functioning and the inflammatory profile of older adults: a systematic review. Curr Opin Clin Nutr Metab Care. 2017;20(1):30-53.

21. Groeneveldt L, Mein G, Garrod R, Jewell AP, Someren KV, Stephens R, et al. A mixed exercise training programme is feasible and safe and may improve quality of life and muscle strength in multiple myeloma survivors. BMC Cancer. 2013;13:31.

22. Coleman EA, Coon S, Hall-Barrow JE, Richards K, Gaylor D, Stewart B. Feasibility of exercise during treatment for multiple myeloma. Cancer Nurs. 2003;26(5):410-9.

23. Fourney DR, Frangou EM, Ryken TC, DiPaola CP, Shaffrey Cl, Berven SH, et al. Spinal instability neoplastic score: an analysis of reliability and validity from the spine oncology study group. J Clin Oncol. 2011;29(22):3072-7.

24. American Thoracic Society. ATS Statement: Guidelines for the six-minute walk test. Statement Guidel Six-Minute Walk Test. 2002(1):111-117.

25. Jones CJ, Rikli RE, Beam WC. A 30-s chair-stand test as a measure of lowe body strength in community-residing older adults. Res Q Exerc Sport. 1999; 70(2):113-9.

26. Roberts HC, Denison HJ, Martin HJ, Patel HP, Syddall H, Cooper C, et al. A review of the measurement of grip strength in clinical and epidemiological studies: towards a standardised approach. Age Ageing. 2011;40(4):423-9.

27. Mijnarends DM, Meijers JMM, Halfens RJG, ter Borg S, Luiking YC, Verlaan S, et al. Validity and reliability of tools to measure muscle mass, strength, and physical performance in community-dwelling older people: a systematic review. J Am Med Dir Assoc. 2013;14(3):170-8.

28. Abizanda P, Navarro JL, García-Tomás MI, López-Jiménez E, MartínezSánchez E, Paterna G. Validity and usefulness of hand-held dynamometry for measuring muscle strength in community-dwelling older persons. Arch Gerontol Geriatr. 2012;54(1):21-7.

29. Mirels H. Metastatic disease in long bones: A proposed scoring system for diagnosing impending pathologic fractures. 1989. Clin Orthop Relat Res. 2003;(415 Suppl):S4-13.

30. Schmidt $K$, Vogt $L$, Thiel $C$, Jäger E, Banzer W. Validity of the six-minute walk test in Cancer patients. Int J Sports Med. 2013;34(07):631-6.

31. Solway $S$, Brooks D, Lacasse $Y$, Thomas $S$. A qualitative systematic overview of the measurement properties of functional walk tests used in the cardiorespiratory domain*. CHEST J. 2001;119(1):256-70.

32. Puggård H, Pedersen KC, Hansen AØ. National Målestandard. Ledmåling - Kraftmåling. Dansk Selskab for Håndterapi; 2013. Available at: https:// www.etf.dk/uploads/uploads/public/national_maalestandard.pdf. Accessed 26 Jan 2020.

33. American Society of Hand Therapists. Clinical Assessment Recommendations. 3 ed: American Society of Hand Therapists. MacDermid, editor. United States of America: American Society of Hand Therapists; 2015.

34. Rikli RE, Jones CJ. Functional fitness normative scores for communityresiding older adults, ages 60-94. J Aging Phys Act. 1999;7:162-81.

35. Dodds RM, Syddall HE, Cooper R, Benzeval M, Deary IJ, Dennison EM, et al. Grip Strength across the Life Course: Normative Data from Twelve British Studies. PLOS ONE. 2014;9(12):e113637.

36. PDA B, Aguiar LT, SAF B, LHN B, Teixeira-Salmela LF, CDCM F, et al. Reference values for muscle strength: a systematic review with a descriptive meta-analysis. Braz J Phys Ther. 2018;22(5):355-69.

37. Vermaete N, Wolter P, Verhoef G, Gosselink R. Physical activity and physical fitness in lymphoma patients before, during, and after chemotherapy: a prospective longitudinal study. Ann Hematol. 2014;93(3):411-24.
38. Alibhai SMH, Breunis H, Timilshina N, Johnston C, Tomlinson G, Tannock I, et al. Impact of androgen-deprivation therapy on physical function and quality of life in men with nonmetastatic prostate Cancer. J Clin Oncol. 2010;28(34):5038-45.

39. Gonzalez BD, Jim HSL, Small BJ, Sutton SK, Fishman MN, Zachariah B, et al. Changes in physical functioning and muscle strength in men receiving androgen deprivation therapy for prostate Cancer: a controlled comparison. Support Care Cancer. 2016;24(5):2201-7.

40. Ortiz A, Tirado M, Hughes DC, Gonzalez V, Song J, Mama SK, et al. Relationship between physical activity, disability, and physical fitness profile in sedentary Latina breast cancer survivors. Physiother Theory Pract. 2018; 34(10):783-94

41. Vardar-Yagli N, Sener G, Saglam M, Calik-Kutukcu E, Arikan H, Inal-Ince D, et al. Associations among Physical Activity, Comorbidity, Functional Capacity, Peripheral Muscle Strength and Depression in Breast Cancer Survivors. Asian Pac J Cancer Prev. 25. 2015;16(2):585-9.

42. Handforth C, D'Oronzo S, Coleman R, Brown J. Cancer treatment and bone health. Calcif Tissue Int. 2018;102(2):251-64.

43. Persoon S, Kersten MJ, Buffart LM, Vander Slagmolen G, Baars JW, Visser O, et al. Health-related physical fitness in patients with multiple myeloma or lymphoma recently treated with autologous stem cell transplantation. J Sci Med Sport. 2017;20(2):116-22.

44. Smith TM, Broomhall CN, Crecelius AR. Physical and psychological effects of a 12-session Cancer rehabilitation exercise program. Clin J Oncol Nurs. 2016; 20(6):653-9.

45. Manual 6-minutter gangtest. Available at: https:/mww.fysio.dk/globalassets/ restricted/fafo/maaleredskaber/6mwt_manual_regionh.pdf. Accessed 27 Aug 2019.

46. Palumbo A, Avet-Loiseau H, Oliva S, Lokhorst HM, Goldschmidt H, Rosinol L, et al. Revised international staging system for multiple myeloma: a report from international myeloma working group. J Clin Oncol. 2015;33(26):2863-9.

47. Landi F, Calvani R, Tosato M, Martone AM, Fusco D, Sisto A, et al. AgeRelated Variations of Muscle Mass, Strength, and Physical Performance in Community-Dwellers: Results From the Milan EXPO Survey. J Am Med Dir Assoc. 2017;18(1):88.e17-24.

48. Casanova C, Celli BR, Barria P, Casas A, Cote C, de Torres JP, et al. The 6-min walk distance in healthy subjects: reference standards from seven countries. Eur Respir J. 2011;37(1):150-6.

49. Chetta A, Zanini A, Pisi G, Aiello M, Tzani P, Neri M, et al. Reference values for the 6-min walk test in healthy subjects 20-50 years old. Respir Med. 2006;100(9):1573-8.

50. Morgan GJ, Child JA, Gregory WM, Szubert AJ, Cocks K, Bell SE, et al. Effects of zoledronic acid versus clodronic acid on skeletal morbidity in patients with newly diagnosed multiple myeloma (MRC myeloma IX): secondary outcomes from a randomised controlled trial. Lancet Oncol. 2011;12(8):743-52.

51. Gan JH, Sim CYL, Santorelli LA. The effectiveness of exercise programmes in patients with multiple myeloma: a literature review. Crit Rev Oncol Hematol. 2016;98:275-89.

52. Jones LW, Alfano CM. Exercise-oncology research: past, present, and future. Acta Oncol Stockh Swed. 2013;52(2):195-215.

53. Buffart LM, Galvão DA, Brug J, Chinapaw MJM, Newton RU. Evidence-based physical activity guidelines for cancer survivors: current guidelines, knowledge gaps and future research directions. Cancer Treat Rev. 2014; 40(2):327-40.

54. Palumbo A, Bringhen S, Mateos M-V, Larocca A, Facon T, Kumar SK, et al. Geriatric assessment predicts survival and toxicities in elderly myeloma patients: an international myeloma working group report. Blood. 2015; 125(13):2068-74.

\section{Publisher's Note}

Springer Nature remains neutral with regard to jurisdictional claims in published maps and institutional affiliations. 